\title{
Investigating the Effect of Modifying Aggregate Surface by Micronized Calcium Carbonate on Increasing the Moisture Resistance of Asphalt Mixtures
}

\author{
Mohsen Sohrabi', Hamid Shirmohammadi ${ }^{1}$, Gholam Hossein Hamedi2* \\ ${ }^{1}$ Department of Civil Engineering, Urmia University, Urmia, Iran \\ 2 Department of Civil Engineering, University of Guilan, Guilan, Iran \\ * Corresponding author, e-mail: hamedi@guilan.ac.ir
}

Received: 21 October 2017, Accepted: 04 October 2018, Published online: 29 October 2018

\begin{abstract}
The adhesion between aggregate and asphalt binder in dry conditions, and the amount of its reduction in wet conditions are amongst fundamental indicators that moisture sensitivity amount of asphalt mixtures is dependent to. Among different methods to increase adhesion, modification of aggregates surface with anti-stripping materials is known as an effective method. Therefore, the effect of covering aggregates surface with micronized calcium carbonate as a proper and inexpensive anti-stripping material was investigated. Accordingly, in order to evaluate mixes, first, mechanical methods were used, and then thermodynamic methods were employed to determine the mechanism of the effect of calcium carbonate on increasing asphalt mix resistance to moisture damage. In order to conduct this research, three types of aggregates including limestone, granite, and quartzite, for their different degrees of hydrophilic, and two types of asphalt binder 60-70 and 85-100 were used to produce mixtures. Results obtained by mechanical methods show that modification of aggregates surface causes an increase in the tensile strength ratio (TSR) in the samples made by both two types of asphalt binder. In addition, results of surface free energy method indicate the increase of adhesion energy (except in granite samples) and reduction of debonding energy in all modified samples. Generally, evaluations conducted by the use of both methods show that covering aggregates by micronized calcium carbonate has a positive effect on reducing moisture sensitivity of asphalt mixes.
\end{abstract}

Keywords

asphalt mixture, moisture damage, micronized calcium carbonate, surface free energy, tensile strength ratio

\section{Introduction}

There are two types of pavements based on design considerations i.e. flexible pavement and rigid pavement. Difference between flexible and rigid pavements is based on the manner in which the loads are distributed to the subgrade [1]. Flexible Pavements are sensitive to water ingress, which degrades the adhesion between bitumen and aggregates and subsequently causes failure [2]. The flexible paving industry is constantly seeking solutions to increase construction efficiency, improve pavement performance, conserve resources and advance environmental stewardship [3].

Moisture damage is regarded as a key effective factor to durability of asphalt pavements. Due to the presence of moisture in the structure of pavement and its destructive effects on adhesion between asphalt binder-aggregate and mastic cohesion, this damage leads to the reduction of mechanical properties of asphalt mixture [4, 5].
Moisture damage in asphalt mixtures has been studied for over 70 years, but a variety of its aspects have remained unknown so far. Two main questions are proposed in this regard:

1. What are the methods that can reduce moisture damages?

2. What are the methods and conditions that can exactly predict damages induced by moisture?

In order to answer the first question, initially we should know how moisture reduces mechanical properties of the mixture so that a proper solution to reduce moisture damages can be presented. So far, 3 mechanisms have been determined that generally led to the reduction of mechanical properties of asphalt mixtures [6].

1. Stripping: losing adhesion

2. Softening: losing cohesion

3. Destruction of aggregates 
Moisture makes its way into pavement structure in various methods. Therefore, mentioned mechanisms may occur as the result of different processes such as thermodynamic, physical, chemical, and mechanical processes. These processes can occur in different ways such as detachment, displacement, dispersion of mastic, desorption of mastic, spontaneous emulsification, and film rupture or micro cracks in asphalt mixture [7].

According to the previous studies [8,9], losing adhesion between asphalt binder and aggregate has been known as the most common type of the mechanisms. This shows that "adhesion" problem is of paramount importance in increasing the strength of asphalt mixtures. Therefore, using any method which firstly avoids from penetration of moisture into the asphalt binder-aggregate interface regions and secondly, increases the adhesion between asphalt binder and aggregate can be useful in reducing moisture damage. Accordingly, some of the effective measures are presented as follows [10]:

1. Modifying physicochemical properties of asphalt mixture and its constituting components (asphalt binder and aggregate), of course by considering economic issues

2. Using methods such as surface sealing and proper drainage to prevent water penetration and rapid discharge of waters penetrated into asphalt mixture

3. Using proper controls at the time of implementation, such as time, temperature, aggregates' moisture control and avoid being exposed to wind and rain, and etc.

4. Proper selection and use of suitable anti-stripping additives in order to increase the interaction of asphalt binder-aggregate with each other (increasing cohesion).

5. Removing materials sensitive to stripping and replacing them with proper materials which is a costly method.

6. Control the characteristics of waters that asphalt mixture is exposed to (in terms of salt percentage and $\mathrm{pH}$ value), and etc.

Among these measures, using anti-stripping materials is known as the most common and effective method to control moisture damage [11]. The main aim of using anti stripping materials in mixes is the improvement of adhesive bonds between asphalt binder and aggregate.

Generally, there are 2 comprehensive approaches to use anti-stripping materials for improving adhesion and reducing moisture sensitivity of asphalt mixtures: the first approach is covering the surface of aggregates with a proper anti-stripping material, and the second approach is strengthening adhesive and cohesive properties of asphalt binder using liquid anti-stripping additives [12]. Besides their advantages, these additives have some disadvantages such as increasing sensitivity to other damages such as rutting [13]. Therefore, using a proper additive with minimum technical and executive problems is considered to be essential. Accordingly, in order to modify the surface of aggregates to increase the adhesion between asphalt binder and aggregate, an anti-stripping material with strong base (Alkali) properties and suitable price was used in the current research, and its effects were evaluated in dry and wet conditions via different methods.

To answer the second question, it can be said that a variety of tests has been developed over years in order to evaluate the effect of anti-stripping additives on moisture sensitivity of asphalt mixtures. The common methods to evaluate moisture sensitivity of asphalt mixtures are based on mechanical tests which are performed on compacted and loose materials. In these tests (e.g., modified Lottman test), the mixtures strength is evaluated generally and materials properties and their role in moisture sensitivity are not measured separately. To put it differently, though these methods evaluate moisture sensitivity of mixtures in terms of mechanical properties, they are incapable of representing physicochemical properties related to adhesion and debonding mechanisms, in a way that to measure moisture sensitivity of mixtures only a mechanical ratio (modulus, tensile strength) when the mixture is conditioned and is not conditioned- is used in this method [5]. Therefore, in order to select high-strength materials, it is essential to correctly determine their properties so that their moisture damages can be predicted and by changing negative properties of materials their sensitivity to moisture can be reduced. Accordingly, the need to a simple and repeatable method capable of conducting the multi-purpose evaluation of asphalt pavement performance in the presence of moisture is feeling. Recently, researchers use new approaches such as surface free energy (cohesion and adhesion energy) [14]. These methods overcome the shortcomings of the common tests, because moisture damage mechanism and the effect of various factors such as the properties of asphalt binder, aggregate and additives on moisture damage can be determined using them. Therefore, in this way the possibility of these damages can be predicted and proper solutions to reduce moisture damage at the time of mixing design can be presented. 


\subsection{Problem statement and the necessity to conduct research}

Considering the importance of the effect of adhesion on moisture damages and reduction of pavement service life, the use of preventive methods such as anti-stripping materials which not only increase mixture performance, but also are economical, is of paramount importance. Additionally, given the previous studies, in order to have a clear image of causes of this damage, micro mechanism evaluation of the effect of materials modification is important besides mechanical evaluations. Therefore, due to the positive performance of micronized calcium carbonate in nano scale in the previous research [15], in the current research attempts have been made to use this additive to modify the surface of lime, granite and quartzite aggregates and evaluate it via various methods. This material is abundant in the nature and has less production and implementation costs compared to production of nano-particles and hydrated lime. Therefore, it is economical, and it can be a suitable alternative to nano-particles of calcium carbonate or hydrated lime if it has an acceptable performance.

The most important objectives of the current research include:

- Measuring surface free energy components of unmodified and modified samples using calcium carbonate powder.

- Identifying the effect of aggregates modification on increasing adhesion energy and reducing debonding energy.

- Investigating the effect of the modification of aggregates surface on moisture sensitivity of asphalt mixtures using mechanical methods.

- Investigating the effect of asphalt binder type on the moisture sensitivity amount of asphalt mixtures made by unmodified and modified aggregates.

- Comparing the results of mechanical and thermodynamic methods in identifying moisture sensitivity of asphalt mixtures.

\section{Surface free energy}

Thermodynamically, the surface free energy of an object is defined as the amount of required work or energy to create a new unit surface to the surface of the same material in vacuum conditions. The work of adhesion $\left(W^{a}\right)$ is a common term usually used in the literature of thermodynamic adhesion theory. Work of adhesion is defined as the required work for detaching 2 connected materials (asphalt binder and aggregate) from each other [16]. Gibbs free energy and work of adhesion are equal and the Equation (1) exists between them.

$W^{a}=-\Delta G^{a}$

Among presented theories to calculate surface free energy of materials, the best known theory is Vanoss-chaudry-good (VOCG) theory [17]. According to this theory free energy of each material is divided into 3 components:

1. Non-polar component or Liftshtiz-van der Waals (LW) component or dispersive component,

2. Lewis acid component, and

3. Lewis base component.

According to this theory, the total surface free energy of all materials is obtained by the Equation (2):

$\Gamma^{\text {total }}=\Gamma^{l w}+\Gamma^{A B}=\Gamma^{L W}+2 \sqrt{\Gamma^{+} \Gamma^{-}}$

where, $\Gamma^{\text {total }}$ is the total surface free energy, $\Gamma^{L^{W}}$ is the nonpolar component, $\Gamma^{+}$is the Lewis acid component, $\Gamma^{-}$is the Lewis base component, $\Gamma^{A B}$ is the acid-base component (polar).

The adhesive bond between asphalt binder and aggregate $\left(W_{s b}^{a}\right)$ can be calculated by substituting surface free energy components of asphalt binder and aggregate in the Equation (3) [18]:

$\left.W_{s b}^{a}=2\left(\sqrt{\Gamma_{s}^{l w} \Gamma_{b}^{l w}}+\sqrt{\Gamma_{s}^{+} \Gamma_{b}^{-}}\right)+\sqrt{\Gamma_{s}^{-} \Gamma_{b}^{+}}\right)$

The cohesion force of asphalt binder is the amount of required energy to create 2 surfaces of a material (here asphalt binder). The asphalt binder cohesion can be calculated using the Rquation (4) and by substituting its surface free energy components [19]. Obviously, the work of cohesion of the asphalt binder (or failure energy) is twice the asphalt binder surface free energy.

$$
\begin{aligned}
& \left.W_{b b}^{a}=2\left(\sqrt{\Gamma_{b}^{l w} \Gamma_{b}^{l w}}+\sqrt{\Gamma_{b}^{+} \Gamma_{b}^{-}}\right)+\sqrt{\Gamma_{b}^{-} \Gamma_{b}^{+}}\right) \\
& =2 \Gamma_{b}^{l w}+4 \sqrt{\Gamma_{b}^{+} \Gamma_{b}^{-}}
\end{aligned}
$$

The adhesion free energy of asphalt binder-aggregate in the presence of water is called debonding energy or work. Its amount can be calculated using the Equation (5):

$W_{b s w}^{w e t}=\Gamma_{b w}+\Gamma_{s w}-\Gamma_{b s}$

where, $\Gamma_{s w}$ is the interfacial energy between aggregate and water $\Gamma_{b w}$ is the interfacial energy between asphalt binder and water $\Gamma_{b s}$ is the interfacial energy between asphalt binder and aggregate. 
The interfacial energy of 2 materials $I$ and $j$ can be calculated using surface free energy components and Eq. (6) [18]:

$$
\left.\Gamma_{i j}=\Gamma_{i}^{\text {total }}+\Gamma_{j}^{\text {total }}-2\left(\sqrt{\Gamma_{i}^{l w} \Gamma_{i}^{l w}}+\sqrt{\Gamma_{i}^{+} \Gamma_{j}^{-}}\right)+\sqrt{\Gamma_{i}^{-} \Gamma_{j}^{+}}\right)
$$

where, $\Gamma_{i}^{\text {total }}, \Gamma_{j}^{\text {total }}$ are total surface free energy of 2 materials, $\Gamma_{i}^{L W} \Gamma_{i}^{-} \Gamma_{i}^{+}$are free energy component of object $i$ $\Gamma_{i}^{L W} \Gamma_{i}^{-} \Gamma_{i}^{+}$are free energy component of object $j$.

By integrating Equations (5) and (6) Eq. (7) is obtained; using this equation the work or energy of adhesion in the presence of water is calculated [6]:

$$
W_{b s a}^{a}=\Gamma_{b w}+\Gamma_{s w}-\Gamma_{b s}=\left[\begin{array}{l}
2 \Gamma_{w}^{l w}+2 \sqrt{\Gamma_{b}^{l w} \Gamma_{s}^{l w}}-2 \sqrt{\Gamma_{b}^{l w} \Gamma_{w}^{l w}} \\
-2 \sqrt{\Gamma_{s}^{l w} \Gamma_{w}^{l w}}+4 \sqrt{\Gamma_{w}^{+} \Gamma_{w}^{-}} \\
-2 \sqrt{\Gamma_{w}^{+}}\left(\sqrt{\Gamma_{b}^{-}}+\sqrt{\Gamma_{s}^{-}}\right) \\
-2 \sqrt{\Gamma_{w}^{-}}\left(\sqrt{\Gamma_{b}^{+}}+\sqrt{\Gamma_{s}^{+}}\right) \\
+2 \sqrt{\Gamma_{b}^{+} \Gamma_{s}^{-}}+2 \sqrt{\Gamma_{b}^{-} \Gamma_{s}^{+}}
\end{array}\right]
$$

The values are important parameters which are used to evaluate moisture damage.

Bhasin et al. [20] presented a parameter called energy parameter to evaluate moisture damage using thermodynamic theories which is defined as Equation (8):

$$
E R=\left|\frac{W_{s b}^{a}}{W_{b s w}^{w e t}}\right|
$$

where, $W_{s b}^{a}$ is the adhesive bond between asphalt binder and aggregate ER is the energy parameter or compatibility ratio, $W_{b s w}^{\text {wet }}$ is the released energy in the presence of moisture or the work of debonding or adhesion free energy in the presence of water

High values of ER indicate less released energy or work of debonding in the presence of water, greater adhesion between asphalt binder and aggregate and consequently high moisture strength.

\section{Materials}

\subsection{Aggregate}

Three types of aggregates including lime stone, granite, and quartzite were used in the current research. The main reason for using these aggregates was their different degrees of hydrophilicity. Using them, the effect of type of aggregates with different minerals and diverse sensitivities to moisture damage was evaluated.

Considering chemical properties of minerals constituting aggregates shown in Table 1, lime aggregates are hydrophobic aggregates and quartzite and granite aggregates are hydrophilic.

The grading used in this research is in the middle of the continuous gradation curves of ASTM standard hot mix asphalt.

Table 1 Percentage of minerals constituting aggregates

\begin{tabular}{|c|c|c|c|c|c|c|c|}
\hline Property & $\begin{array}{c}\text { Specific gravity at } \\
25^{\circ} \mathrm{C}, \mathrm{g} / \mathrm{cm}^{3}\end{array}$ & $\begin{array}{c}\text { Penetration } \\
\left(100 \mathrm{~g}, 5 \mathrm{~s}, 25^{\circ} \mathrm{C}\right), \\
0.1 \mathrm{~mm}\end{array}$ & $\begin{array}{l}\text { Softening } \\
\text { point, }{ }^{\circ} \mathrm{C}\end{array}$ & $\begin{array}{c}\text { Ductility } \\
\left(25^{\circ} \mathrm{C}, 5 \mathrm{~cm} / \mathrm{min}\right), \\
\mathrm{cm}\end{array}$ & $\begin{array}{c}\text { Flash } \\
\text { point, }{ }^{\circ} \mathrm{C}\end{array}$ & $\begin{array}{c}\text { Loss of } \\
\text { heating, \% }\end{array}$ & $\begin{array}{c}\text { Solubility in } \\
\text { trichloroethylene, } \\
\%\end{array}$ \\
\hline \multirow{2}{*}{ Standard } & ASTM & ASTM & ASTM & ASTM & ASTM & ASTM & ASTM \\
\hline & D70-76 & D5-73 & D36-76 & D113-79 & D92-78 & D1754-78 & D2042-76 \\
\hline The allowable amount & - & $60-70$ & $49-56$ & Min100 & Min 232 & - & - \\
\hline $60-70$ & 1.02 & 66 & 51 & 105 & 262 & 0.75 & 99.5 \\
\hline The allowable amount & - & $85-100$ & $45-52$ & Min 100 & Min 232 & - & - \\
\hline $85-100$ & 1.03 & 91 & 48 & 112 & 248 & 0.75 & 99.5 \\
\hline
\end{tabular}

\begin{tabular}{lccccc}
\hline Aggregate & Silico dioxide, $\mathrm{SiO}_{2}$ & Aluminium oxide, $\mathrm{Al}_{2} \mathrm{O}_{3}$ & Ferric oxide, $\mathrm{Fe}_{2} \mathrm{O}_{3}$ & Magnesium oxide, $\mathrm{MgO}$ & $\mathrm{Calcium}$ oxide, $\mathrm{CaO}$ \\
\hline Limestone & 16.58 & 4.84 & 3.87 & 2.24 & 72.47 \\
Granite & 52.19 & 6.05 & 7.08 & 2.92 & 31.75 \\
Quartzite & 66.96 & 13.67 & 4.09 & 1.76 & 13.53 \\
\hline
\end{tabular}

Table 2 Characteristics of the asphalt binders used in this research

Table 3 Chemical properties of calcium carbonate powder

\begin{tabular}{lcccccccccc}
\hline Sample & $\mathrm{SiO}_{2}$ & $\mathrm{Al}_{2} \mathrm{O}_{3}$ & $\mathrm{Fe}_{2} \mathrm{O}_{3}$ & $\mathrm{CaO}$ & $\mathrm{Na}_{2} \mathrm{O}$ & $\mathrm{K}_{2} \mathrm{O}$ & $\mathrm{MgO}$ & $\mathrm{TiO}_{2}$ & $\mathrm{MnO}_{2}$ & $\mathrm{P}_{2} \mathrm{O}_{5}$ \\
\hline $\mathrm{CaCO}_{3}$ & 0.14 & 0.07 & 0.02 & 56.82 & 0.06 & 0.01 & 0.26 & 0.001 & 0.001 & 0.82 \\
\hline
\end{tabular}




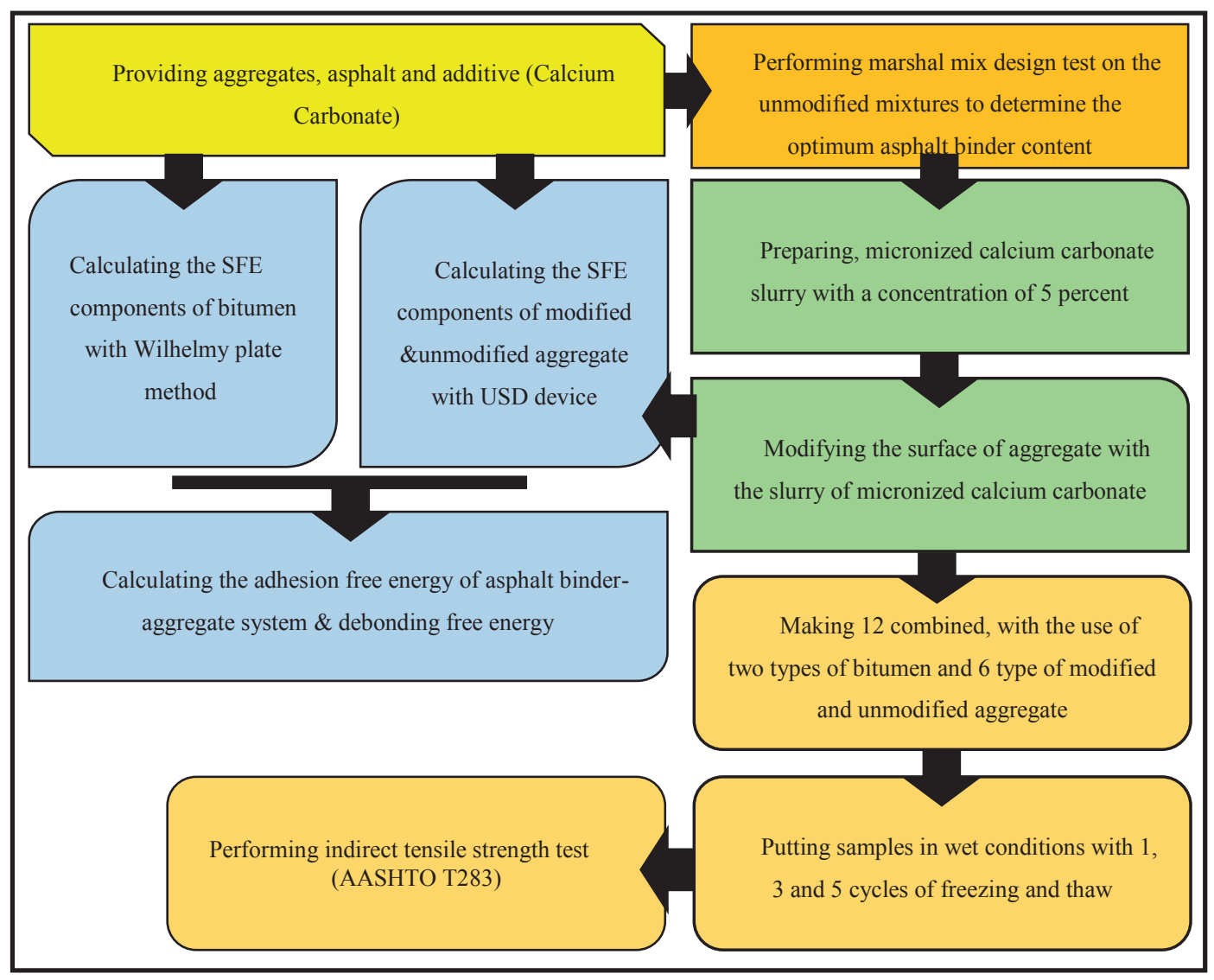

Fig. 1 Laboratory program algorithm

\subsection{Asphalt binder}

Moisture damage usually occurs due to heavy traffic in cold and rainy regions in which asphalt binders with medium penetration degrees (60-70 and 85-100) are used. Accordingly, the mentioned asphalt binders from Pasargad Oil Company were prepared. These asphalt binder's properties are presented in Table 2.

\subsection{Calcium carbonate}

Due to its base properties and its fair price, micronized calcium carbonate powder $\left(\mathrm{CaCO}_{3}\right)$ is used to modify aggregates surface. Powder used in this research was supplied by Poudrsazan Azadi Company. The chemical properties of powder are shown in Table 3.

\section{Laboratory program}

Tests were performed via 2 general processes in this research:

1. A process to evaluate mixes by thermodynamic method

2. A process to perform modified Lottman mechanical test.

The experimental flowchart of this study is shown in Fig 1.

\subsection{Mix design}

In order to determine the optimum asphalt binder contents, Marshall mix design based on ASTM D1559 standard [21] was used in this research. It should be noted that it is supposed the modification of aggregates make no difference in the optimum asphalt binder content of unmodified and modified samples, because using different percentages of asphalt binder increases the possibility of error occurrence in the analysis of results. Thus mix design test was performed only for 6 main compounds ( 2 asphalt binder types and 3 aggregate types), and asphalt binder percentages obtained for modified aggregates were used as well.

\subsection{Modification of aggregate surface}

In order to cover aggregates surface with calcium carbonate, first, calcium carbonate slurry should be prepared. Accordingly, first, 5 units of micronized calcium carbonate powder crushed in a mill is added to 100 units of water (this amount obtained experimentally in laboratory). Then this mixture is stirred using a hydrometric mixer with a speed of $200 \mathrm{rpm}$ for 4 minutes. When calcium carbonate particles were distributed homogeneously in the water space, the aggregates are added to the mixture. The 
Table 4 The percentage of carbonate calcium absorbed by the aggregate surface

\begin{tabular}{lccc}
\hline Aggregate type & Limestone & Granite & Quartzite \\
\hline $\begin{array}{l}\text { Adsorbed percent based on } \\
\text { the weight of aggregates }\end{array}$ & 2.8 & 2.3 & 2.1 \\
\hline
\end{tabular}

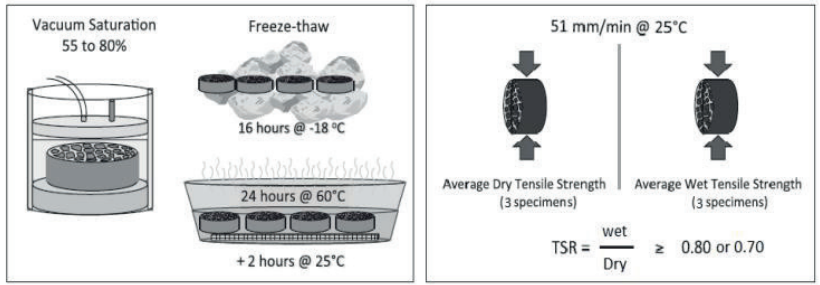

Fig. 2 The method of conditioning and loading specimens in the modified Lottman test [22]

obtained mixture is stirred for 2 minutes with a speed of $30 \mathrm{rpm}$ until the entire surface of the aggregates is covered by slurry. At the next stage, the wet aggregates, on them the slurry coverage has been formed, are distributed on the surface of the steel mesh vessel. After 2 hours, the aggregates are placed into the oven for $24 \mathrm{~h}$ at $110 \mathrm{C}^{\circ}$, so that the moisture in them can be completely evaporated. The mass percentage of the absorbed calcium carbonate particles can be measured after drying. Table 4 shows the adsorbed percentages of mass of calcium carbonate particles relative to the mass of total aggregates. As shown, the percentage of the absorbed calcium carbonate by lime stone aggregates is higher. This was expected, because lime stone aggregates have a more porous structure compared to granite and quartzite aggregates. The percentage of the absorbed particles is subtracted from the percentage of the filler which is going to be used. In fact, the absorbed calcium carbonate particles were regarded as a part of filler.

\subsection{Modified Lottman test (AASHTO T283)}

AAHTO T283 test is the most common laboratory test to evaluate moisture damage of asphalt mixtures. In this test, a horizontal cylindrical sample is placed under vertical loading. This loading leads to tension stress along with its diameter and thus cracking and failure of the sample.

In order to perform this test, 6 samples are needed for each compound. Three samples are placed under wet conditions and 3 samples are remained under dry conditions. According to Fig. 2, in order to condition mixtures, after producing compacted samples with an air percentage of $6.5-7.5 \%, 3$, samples of each compound are saturated under relative vacuum conditions with a saturation percentage of 55-80\%. Saturated samples are placed into plastic bags and $10 \mathrm{ml}$ water is added to them. Samples are kept into freezer at $-18 \mathrm{C}^{\mathrm{o}}$ for $16 \mathrm{~h}$. then they are put into hot water bath at $60 \mathrm{C}^{\mathrm{o}}$, plastics are removed and samples are allowed to remain at this temperature for $24 \mathrm{~h}$. In the following, samples are placed in the room temperature $\left(25 \mathrm{C}^{\circ}\right)$ for $2 \mathrm{~h}$. These samples are called wet samples.

After these stages, wet and dry samples are put under indirect tensile strength test. In the indirect tensile strength test, loading is performed with a rate of $5.08 \mathrm{~cm} / \mathrm{min}$ until failure occurs. The load amount at failure moment is recorded and finally indirect tensile strength for all 6 samples is obtained using Eq. (9).

$$
I T S=\frac{2000 F}{t \pi d}
$$

where, ITS is the amount of indirect tensile strength (kpa), $F$ is the amount of force at failure moment (fracture load) $(\mathrm{N}), t$ is the thickness of asphalt sample (mm), and $d$ is the sample diameter $(\mathrm{mm})$.

The mean of tensile strength of dry samples (3 samples) and wet samples (3 samples) are calculated separately. Moisture sensitivity or stripping potential of asphalt mixture with the mean of indirect tensile strength of wet samples to dry samples ratio in \% is obtained as Equation (10):

$T S R=\left(\frac{I T S_{w e t}}{I T S_{d r y}}\right) \times 100$

where, TSR is the indirect tensile strength ratio (\%), ITS is the mean of indirect tensile strength of wet samples (kpa), ITS $S_{d r y}$ is the mean of indirect tensile strength of dry samples (kpa).

\subsection{Calculating surface free energy components}

In order to measure surface free energy components of aggregate and asphalt binder Universal sorption device (USD) and Wilhelmy Plate (WP) were used, respectively.

\subsubsection{Measuring surface free energy components of aggregates}

It is rarely possible to directly measure surface free energy components of a solid object. The more efficient method is determining solid object components by measuring the work of adhesion between the solid object and materials whose surface free energy components are known. These materials that help determine solid object's surface free energy components are called probe liquids.

The work of adhesion between aggregate and probe liquids vapor for high-surface free energy materials such as aggregates can be determined by adsorption isotherm. 
An adsorption isotherm is a relationship between liquid pressure and the absorbed vapor mass on the solid surface. Using USD, equilibrium spreading pressure $\left(\pi_{e}\right)$ of probe liquids vapor on the aggregates surface can be calculated and by substituting them in Eq. (11), 3 equations with 3 unknowns are formed; the unknowns are free energy components of aggregates. $V$ and $s$ indices refer to probe liquids vapor and the solid object, respectively.

$$
\left.W_{s v}^{a}=2 \Gamma_{v}^{\text {total }}+\pi_{e}=2\left(\sqrt{\Gamma_{s}^{l w} \Gamma_{v}^{l w}}+\sqrt{\Gamma_{s}^{+} \Gamma_{v}^{-}}\right)+\sqrt{\Gamma_{s}^{-} \Gamma_{v}^{+}}\right)
$$

where, $W_{s v}^{a}$ is the work of adhesion between aggregate and the vapor of liquids under testing, $\Gamma_{v}^{\text {total }}$ is the total surface free energy of liquids under testing, $\pi_{e}$ is the equilibrium spreading pressure of liquid vapor on the solid surface which is obtained by the Equation (12)

$$
\pi_{e}=\frac{R T}{M A} \int_{0}^{P n} \frac{n}{p} d p
$$

where $R$ is the universal gas constant $(8.314 \mathrm{~J} / \mathrm{Kmol}), T$ is the test temperature (Kelvin), $M$ is the molecular mass of tested liquid vapor, $N$ is the mass of the absorbed vapor per unit aggregate mass in vapor pressure $p, A$ is the Specific surface area of aggregate which is calculated using Branauer, Emmett, and Teller (BET) classic relation based on Equations (13)

$$
A=\left(\frac{n_{m} N_{0}}{M}\right) \alpha
$$

Where $N_{0}$ is the Avogadro's number, $\alpha$ is the imaged surface of a molecule, $n_{m}$ is the monolyer capacity which is equal to the number of required molecules to cover aggregate surface in a layer; it is obtained by Equation (14):

$$
n_{m}=\left(\frac{1}{S+I}\right)
$$

Where $S, I$ are the slope and intercept of the graph of the relationship between $P / n\left(P_{n}-P\right)$ and $P / P_{n}, P$ is the partial vapor pressure, $P_{n}$ is the saturated vapor pressure, $n$ is the mass of the absorbed vapor to the mass of the aggregate.

\subsubsection{Measuring surface free energy components of asphalt binder}

Wilhelmy Plate method is to measure the contact angle between asphalt binder and a liquid. According to the Fig. 3, this method is performed based on the equilibrium of Kinetic forces of a very thin plate which is being emerged or withdrawn from a liquid under a constant and very low speed.

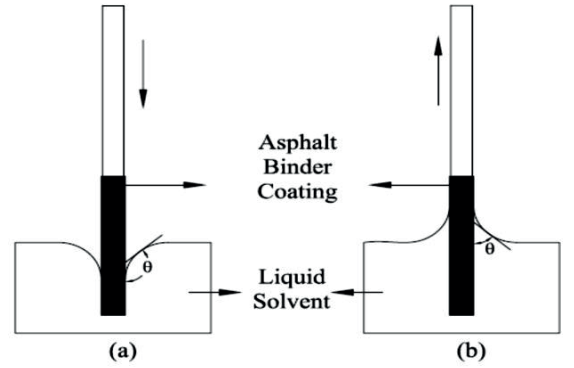

Fig. 3 Wilhelmy Plate test, (a) advancing contact angle, (b): receding contact angle

When the plate is suspended in the air, the required force to hold it in equilibrium state is calculated from Equation (14):

$$
F=W_{\text {Plate }}+W_{\text {asphalt }}-V \cdot \rho_{\text {air }} \cdot g
$$

Where, $F$ is the required force to hold stable the plate, $W_{\text {plate }}$ is the weight of the glass plate, $W_{\text {asphalt }}$ is the asphalt binder weight, $V$ is the volume of the asphalt plate, $\rho_{\text {air }}$ is the specific weight of the air, and $g$ is local acceleration of gravity.

When the plate that coated with asphalt film immersed in a fluid, Equation (14) is converted to Equation (15):

Where, $P_{t}$ is the periphery of the asphalt coated plate, $\Gamma_{l}$ is total surface free energy of the liquid, $\theta$ is the dynamic contact angle between asphalt binder and test liquid, $V_{i m}$ is the volume of the immerged part of the plate coverd with asphalt binder; $V$ is total volume of asphalt binder plate and $\rho_{l}$ is the specific weight of the liquid

By subtracting Equation (15) from Equations (16-17) is obtained:

$$
\begin{aligned}
& F=W_{\text {Plate }}+W_{\text {asphalt }}+P_{t} \Gamma_{l} \cos \theta \\
& -V . \rho_{l} \cdot g-\left(V-V_{\text {im }}\right) \rho_{\text {air }} \cdot g
\end{aligned}
$$

By rewriting the Equation (16), the contact angle is obtained using parameters of the right side of the equation which are calculated when the test is performed [23].

$\cos \theta=\frac{\Delta F+V_{i m}\left(\rho_{l}-\rho_{\text {air }}\right) g}{p_{t} \Gamma_{l}}$

Based on Young-Dupre equation, Vanoss et al. [24] expressed the equation between contact angle and surface free energy components as Equation (18):

$$
\Gamma_{v}^{\text {total }}(1+\cos \theta)=2\left(\sqrt{\Gamma_{b}^{l w} \Gamma_{l}^{l w}}+\sqrt{\Gamma_{b}^{+} \Gamma_{l}^{-}}+\sqrt{\Gamma_{b}^{-} \Gamma_{l}^{+}}\right)
$$

Where $\Gamma_{b}^{L W}, \Gamma_{b}^{+}, \Gamma_{b}^{-}$are the Surface free energy components of the asphalt binder, $\Gamma_{l}^{\text {total }}$ and $\Gamma_{l}^{L W}, \Gamma_{l}^{+}, \Gamma_{l}^{-}$are the surface free energy components of liquid solvent, $\theta$ is the ontact angle obtained using Wilhelmy Plate test. 


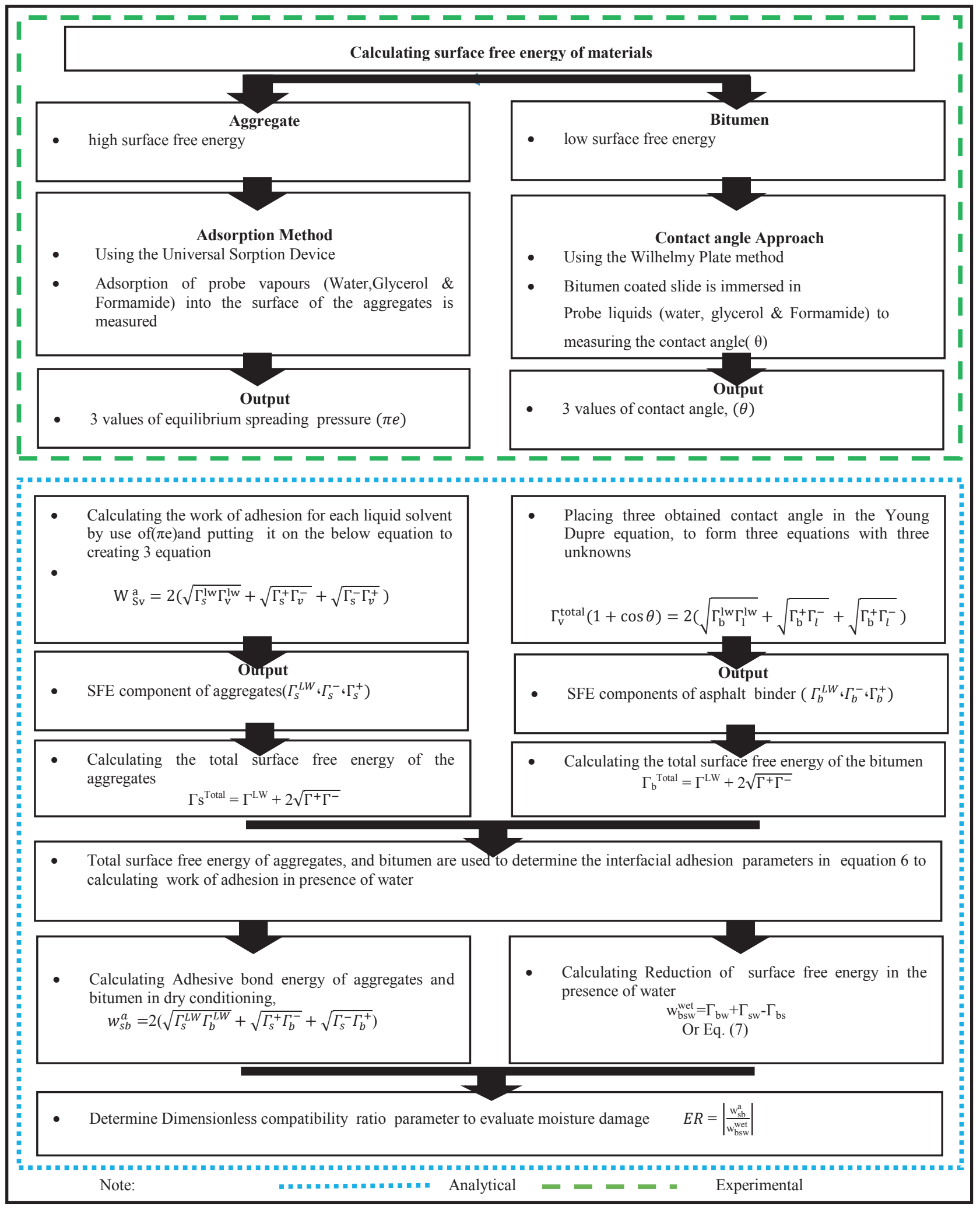

Fig. 4 Calculation algorithm and evaluation of mixtures moisture sensitivity based on surface free energy method [28] 


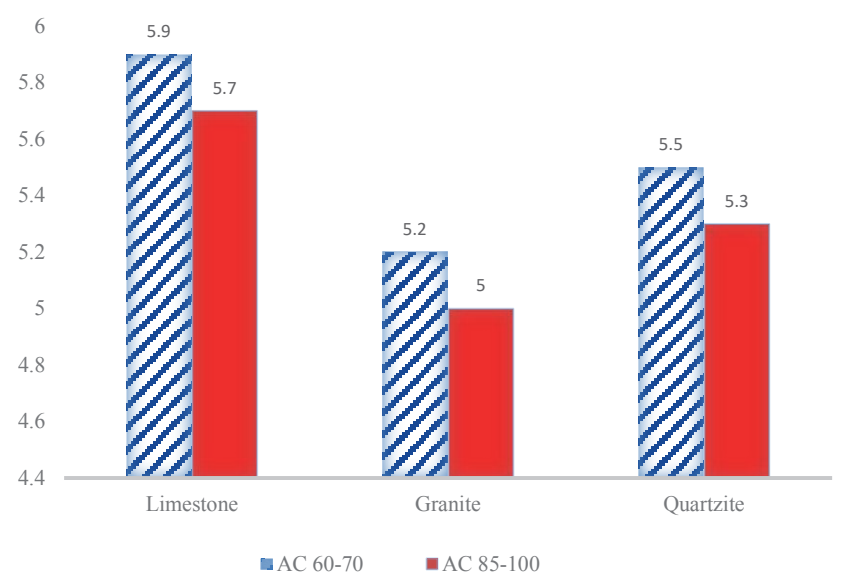

Fig. 5 Optimum asphalt binder content for aggregate and asphalt binder types

The details of SFE components of aggregates and asphalt binders are presented in the Fig. 4 .

Specifications of the probe liquids used in this research are can be seen in the Table 5 .

\subsubsection{Evaluation of moisture damage using SFE method} As observed, in order to evaluate moisture damage using surface free energy theory, a set of tests and theoretical equations are used. Therefore, in order to simply understand this theory-laboratory method, a summary of the process of calculating surface free energy of materials and finally moisture damage evaluation is presented as a flowchart.

\section{Results and discussion}

\subsection{Mix design results}

Results obtained by Marshal mix design tests for 6 unmodified compounds can be seen in the Fig. 5 .

As shown in the Fig. 5, the optimum asphalt binder content (\%) for lime aggregate is more than granite and quartzite aggregates. This is due to the more porosity of the limestone aggregates and more absorption of this type of aggregates relative to granite and quartzite aggregates. In addition, it can be observed that the optimum asphalt binder content for asphalt binders with less penetration grade (60-70) is greater.

The reason is that the higher viscosity, the less ability to penetrate into aggregates pores and consequently a greater amount of asphalt binder is needed to well cover the aggregates surface.

\subsection{Moisture sensitivity test results}

Considering the Figs. 6-7, TSR of samples decreased by increasing freeze-thaw cycles. Samples made by asphalt binder $60-70$ showed a better performance compared to

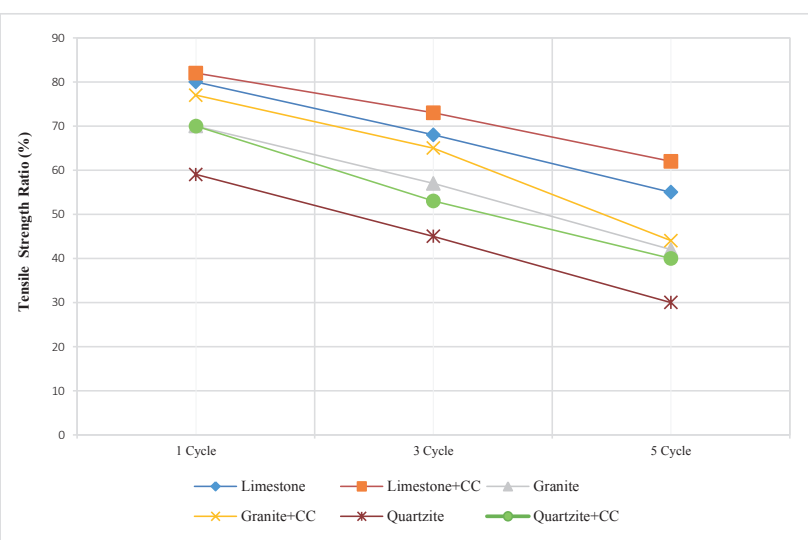

Fig. 6 Indirect tensile strength ratio for unmodified and modified samples made by asphalt binder $85-100$

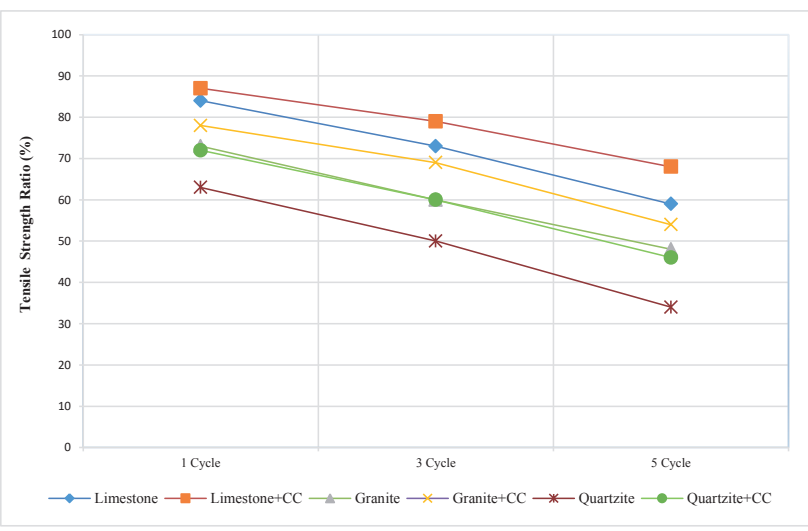

Fig. 7 Indirect tensile strength ratio for unmodified and modified samples made by asphalt binder 60-70

those made by asphalt binder 85-100. In addition, it is observed that the use of anti-stripping micronized calcium carbonate additive led to the improvement of the strength of modified asphalt mixtures in all samples compared to control samples. For both types of asphalt binders, the values of TSR for unmodified and modified lime aggregates are greater. In the other words, lime aggregates showed maximum resistance to moisture damage, while quartzite aggregates have the minimum resistance to moisture damage. This result was obtained in the previous research as well $[25,12]$.

From the results of TSR test, it is found that the modification of the surface of all aggregates in wet conditions has positive effect. This increase in the TSR can be due to the improvement of adhesion amount in the modified samples. As calcium carbonate particles have base properties, it has been able to increase the amount of adhesion between asphalt binder and aggregates, especially for quartzite acidic aggregates, in a way that in the samples made by asphalt binder 60-70 and in 5 freeze-thaw cycles TSR undergoes change by $26.10 \%$ and $25 \%$ in asphalt binder $58-100$. 


\subsection{Results of free energy tests}

\subsubsection{Measuring surface free energy of bitumen using Wilhelmy Plate}

Asphalt binder is a single-phase, homogeneous mixture of polar and non-polar molecules, including asphaltenes and maltenes. These materials themselves include aromatics, resins and paraffin. Most of the molecules constituting asphalt binder have acidic and non-polar properties. The asphalt binder polar compound's interactions determine its structure and mechanical properties, in a way that non-polar molecules act as a solvent to put polar molecules (asphaltenes) besides each other. Therefore, asphalt binder is known as a material with acidic properties capable of having a proper reactivity with particles which have basic properties, and creates an acceptable adhesion. Therefore it can be expected that acidic components will be greater than basic components, in addition, non-polar components of asphalt binders will be greater than their polar components.

Results presented in Table 6 for asphalt binders used in this research approve the mentioned matters.

\subsubsection{Measuring surface free energy components of aggregates}

Table 7 shows the results of measuring surface free energy components of aggregates. Results show that the modification of aggregates surface has led to the reduction and increase of acid and basic components of all 3 types of aggregates, respectively. As asphalt binder is known as an acid material, these changes lead to the better adhesion between asphalt binder and aggregates, especially for acidic aggregates.

In addition, results indicate that the modified aggregates have less polar components compared to unmodified samples. According to the previous research, the polarity amount of aggregates indicates the existence of a high percentage of silicone dioxide mineral in them [26], the values presented in Table 1 confirms this. Therefore, the reduction of aggregates polarity leads to the reduction of hydrophilicity and increase of adhesion with asphalt binder which is a non-polar material. Accordingly, calcium carbonate affects at most lime aggregates and then granite and quartzite aggregates and can reduce $16.58,10.33$, and $8.43 \%$ of polar components of lime, granite and quartzite aggregates, respectively.

Results of Table 7 show that modification of the aggregates surface has caused an increase in non-polar component in lime and granite aggregates, this leads to the increase of aggregates adhesion with asphalt binder (which is a non-polar material) by creating covalent bonds. On the other hand, increasing non-polar properties which is equal to the reduction of polar properties leads to the reduction of aggregates tendency to be adhered and wetted by water.

Finally, it is observed that the use of calcium carbonate coating on the aggregates surface causes a reduction in the total surface free energy of the aggregates. This change leads to the increase of wettability of aggregates. The reduction values of total surface free energy were higher for lime and granite aggregates, respectively, but its effect on quartzite aggregates was less.

\subsection{Adhesion free energy}

Adhesion free energy is one of the important parameters in determination of adhesive strength of asphalt mixtures. Adhesion free energy is defined as the required amount of energy to debond asphalt binder film from unit surface area of aggregate [27]; the greater amount of this energy means the high resistance of the mix to stripping.

After measuring surface free energy components of asphalt binder and aggregate and having surface free energy components of water which are presented in Tables

Table 5 Surface free energy components of test liquids in Wilhelmy plate method $\left(\mathrm{ergs} / \mathrm{cm}^{2}\right)$

\begin{tabular}{lcccc}
\hline Liquid solvent & \multicolumn{3}{c}{ SFE components ergs/cm } \\
& $\Gamma^{+}$Acidic & $\Gamma^{-}$Base & $\Gamma^{\mathrm{AB}}$ Polar & $\Gamma^{\mathrm{LW}}$ Nonpolar \\
\hline Water & 25.5 & 25.5 & 51 & 21.8 \\
Glycerol & 3.92 & 57.4 & 30 & 34 \\
Formamide & 2.28 & 39.6 & 19 & 39 \\
\hline
\end{tabular}

Table 6 Surface free energy components of the asphalt binders $\left(\mathrm{ergs} / \mathrm{cm}^{2}\right)$

\begin{tabular}{lcccc}
\hline \multirow{2}{*}{ Asphalt binder } & \multicolumn{3}{c}{ SFE components ergs/cm ${ }^{2}$} & $\Gamma^{\mathrm{LW}}$ \\
\hline AC 60-70 & $\Gamma^{+}$ & $\Gamma^{-}$ & $\Gamma^{\mathrm{AB}}$ & 14.01 \\
AC 85-100 & 1.89 & 0.68 & 2.27 & 16.28 \\
\hline
\end{tabular}


Table 7 Surface free energy components for used aggregates $\left(\mathrm{ergs} / \mathrm{cm}^{2}\right)$

\begin{tabular}{|c|c|c|c|c|c|}
\hline \multirow{2}{*}{ Aggregate type } & \multicolumn{5}{|c|}{ SFE components ergs $/ \mathrm{cm}^{2}$} \\
\hline & $\Gamma^{+}$Acidic & $\Gamma^{-}$Base & $\Gamma^{\mathrm{AB}}$ Polar & $\Gamma^{\mathrm{LW}}$ Nonpolar & $\Gamma^{\mathrm{t}}$ Total \\
\hline Limestone & 21.3 & 508.9 & 208.2 & 67.2 & 275.4 \\
\hline Limestone $+\mathrm{CC}$ & 14.6 & 516.7 & 173.7 & 79.3 & 253.0 \\
\hline Granite & 34.1 & 531.2 & 269.2 & 68.1 & 337.3 \\
\hline Granite $+\mathrm{CC}$ & 27.0 & 539.5 & 241.4 & 69.2 & 310.6 \\
\hline Quartzite & 41.3 & 492.1 & 285.1 & 57.1 & 342.2 \\
\hline Quartzite $+\mathrm{CC}$ & 32.8 & 519.6 & 261.1 & 56.9 & 318.0 \\
\hline
\end{tabular}

5-7, respectively, the asphalt binder-aggregate, water-asphalt binder, and water-aggregate adhesion can be calculated using Equation (3). It should be noted that as water-asphalt binder and water-aggregate adhesion are created after stripping occurred, these parameters are not considered as parameters affecting moisture damage occurrence and in the following only adhesion free energy of asphalt binder-aggregate and adhesion free energy in the presence of water are investigated.

Given calculated values in Table 8 it is observed that the adhesion energy between asphalt binder and quartzite aggregates is lower compared to granite and lime aggregates; this can be due to acidic properties of quartzite aggregates.

In lime aggregates, calcium carbonate coating has increased adhesion energy amounts in mixes made by 2 types of asphalt binder $60-70$ and $85-100$, but it had no effect on increasing adhesion energy of granite and quartzite aggregates in mixes made by both types of asphalt binders, but in dry condition it has slightly reduced the adhesion between asphalt binder and granite aggregates.

Comparing values related to 2 types of used asphalt binders it can be found that the asphalt binder type had no effect on increasing adhesion free energy of mixes, in the other words, the percentage of adhesion changes for both types of asphalt binders is similar.

Debonding energy parameter is one of the other important cases to be considered for evaluation of moisture damage of asphalt mixes. This parameter is equal to the adhesion energy between asphalt binder and aggregates in the presence of water. Its values can be calculated using adhesion free energy components of asphalt binder, aggregate and water and Equation (7). Calculations show that debonding energy in the presence of water is negative. This means that all asphalt mixes will undergo stripping in the presence of water but the severity and speed of this phenomenon is different in them. The more negative debonding energy indicates that the amount of released energy from asphalt binder and aggregate mix reaction in the presence of water (stripping) has been grater and the mixture is more sensitive to moisture damage. In the other words, when water enters into asphalt binder and aggregate system, the mixture becomes instable and in order to reach a stable state it should release energy. Therefore, the process of debonding aggregate and asphalt binder in the presence of water is spontaneous. It should be noted that for the sake of results analysis simplicity, the absolute value of debonding energy is considered in this research.

Considering results of Table 8 , it is observed that the absolute value of debonding energy is greater for unmodified compounds. This shows the higher potential of these compounds to moisture sensitivity. In addition, it can be observed that debonding energy of lime aggregates is less than the other 2 types of aggregates. Of course, this was expected due to the hydrophobicity property of lime aggregates.

Using the hydrophobic coating of calcium carbonate caused a reduction in debonding energy in all samples. The most amount of changes occurred in samples made by lime aggregates, asphalt binder 85-100, and asphalt binder 60-70, respectively, then granite and quartzite aggregates.

Additionally, it is observed that the asphalt binder type was not an important parameter in the amount of debonding energy for asphalt mixtures used in this research, in a way that no significant differences in debonding energy of unmodified and modified samples were not seen for samples made by 2 types of asphalt binders (e.g., the modification of aggregates for lime aggregates and asphalt binder 60-70 caused a change in debonding energy by $3.2 \%$ and this difference for lime samples and asphalt binder 85-100 was 3.3\%). But, considering the results, it can be found that samples made by asphalt binder 60-70 has less debonding energy compared to samples made by asphalt binder 85-100, showing that damage potential of samples made by asphalt binder $60-70$ is less than samples made by asphalt binder $85-100$. 
Table 8 Adhesion free energy components $\left(\mathrm{ergs} / \mathrm{cm}^{2}\right)$

\begin{tabular}{lccccc}
\hline Aggregate & Asphalt binder & $\begin{array}{c}\text { Asphalt } \\
\text { binder-aggregate }\end{array}$ & Asphalt-water & Water-aggregate & $\begin{array}{c}\text { Asphalt-asphalt binder } \\
\text { in presence of water }\end{array}$ \\
\hline Limestone & AC $60-70$ & 131.0 & 57.2 & 351.0 & -131.6 \\
Limestone+CC & AC $60-70$ & 135.5 & 57.2 & 351.3 & -127.4 \\
Granite & AC $60-70$ & 134.8 & 57.2 & 368.8 & -145.6 \\
Granite+CC & AC $60-70$ & 134.7 & 57.2 & 364.7 & -141.6 \\
Quartzite & AC $60-70$ & 128.2 & 57.2 & 359.5 & -142.9 \\
Quartzite+CC & AC $60-70$ & 128.6 & 57.2 & 358.5 & -141.5 \\
Limestone & AC $85-100$ & 129.8 & 58.0 & 351.0 & -133.7 \\
Limestone+CC & AC $85-100$ & 134.4 & 58.0 & 361.3 & -129.3 \\
Granite & AC $85-100$ & 133.5 & 58.0 & 364.7 & -147.8 \\
Granite+CC & AC $85-100$ & 133.4 & 58.0 & 359.5 & -143.8 \\
Quartzite & AC $85-100$ & 126.8 & 58.0 & 358.5 & -145.2 \\
Quartzite+CC & AC $85-100$ & 127.1 & 58.0 & & -143.9 \\
\hline
\end{tabular}

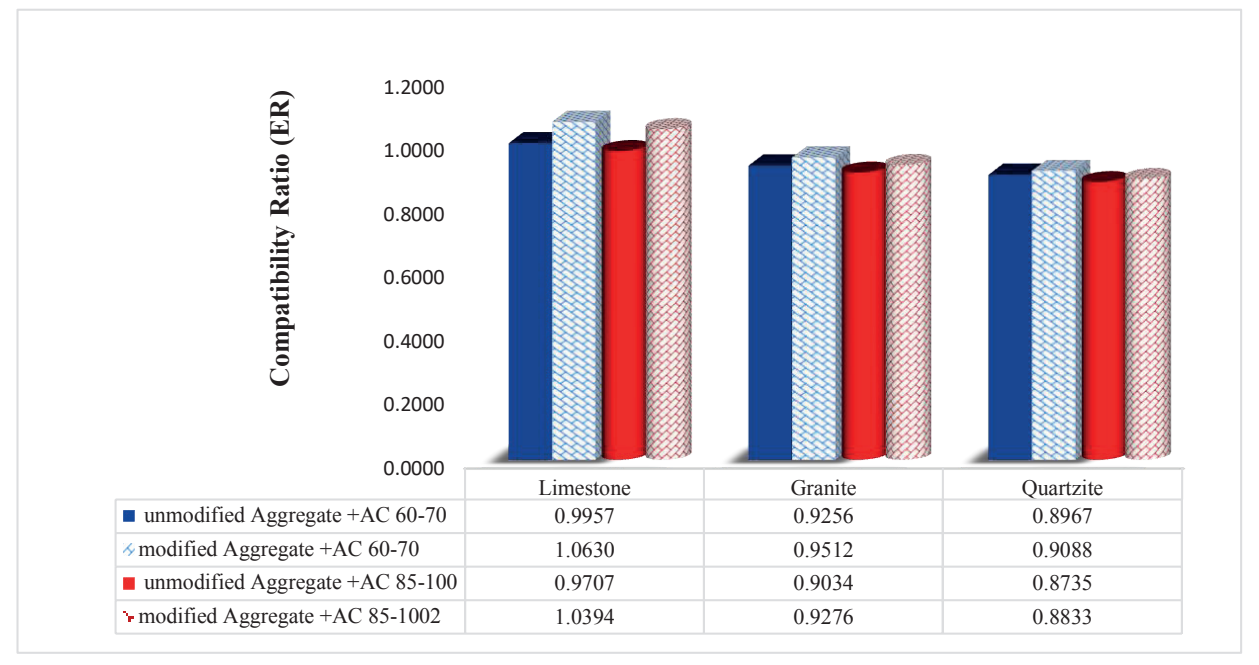

Fig. 8 Energy ratio

\subsection{Energy parameters}

Bhasin et al. [20] presented ratios to evaluate moisture damage. One of them is energy ratio (compatibility ratio) ERI (Energy Rating Index) which is equal to the absolute value of adhesion work to debonding work ratio. The high values of this ratio show higher resistance of the mixture to moisture damage. In the Fig. 8, ERI values of the obtained results are shown.

Considering the Fig. 8 it is found that the values of energy ratio for lime aggregates are higher and granite aggregates and quartzite aggregates stand in the next places. The modification of aggregate surface led to the improvement of this ratio in all samples.

Samples made by asphalt binder $60-70$ have greater values compared to samples made by asphalt binder $85-100$.

All the mentioned matters are in agreement with results of the modified Lottman mechanical test.

\section{Conclusions}

This research was conducted with the aim to evaluate the effect of using micronized calcium carbonate to cover and modify aggregates surface on the reduction of moisture damage of asphalt mixes. Accordingly, 2 different mechanical and thermodynamic methods were used to evaluate mixes, so that not only moisture sensitivity of the unmodified and modified mixtures can be investigated, but also damage mechanism and the effect of the mentioned additive can be evaluated. The most important results obtained are presented in the following section:

1. The modification of the aggregates surface with micronized powder of calcium carbonate leads to the increase of TSR values and ITS of samples in wet condition, in a way that ITS and TSR values for samples made by asphalt binder $60-70$ are greater than samples made by asphalt binder $85-100$. Therefore, 
the strength of samples made by asphalt binder 60-70 is higher.

2. Due to its base properties, the coating of calcium carbonate on the aggregates surface leads to the reduction and increase of acidic and basic components of aggregates, respectively.

3. The use of calcium carbonate has reduced polar components of aggregates. This reduction (or increase of non-polar component) has caused an increase in the aggregates tendency to oil and reduction of their tendency to adhesion and getting wet by a polar material such as water. The maximum effect of calcium carbonate on reducing polar components is in lime aggregates and then granite and quartzite aggregates; it has been able to reduce polar components by $16.58,10.23$, and $8.43 \%$ in lime, granite and quartzite aggregates, respectively.

4. The aggregates surface coating causes an increase in non-polar components of lime and granite aggregates, but this component values have reduced for quartzite aggregates. The increased non-polar aggregates via creating covalent bonds, leads to the increase of aggregate-asphalt binder adhesion (which is a non-polar material).

5. Using calcium carbonate coating on the lime aggregates has increased asphalt binder-aggregate adhesion in mixes made by 2 types of asphalt binder 60-70 and 85-100. But, in granite and quartzite aggregates it had no effect on increasing adhesion energy between aggregate-asphalt binder for mixes made by both types of asphalt binders and it has slightly decreased the amount of adhesion for granite aggregates in dry condition.

6. Comparing adhesion energy values related to both types of asphalt binders it can be found that the asphalt binder type had no effect on increasing adhesion free energy of mixtures. In the other words, the percentage of adhesion changes of modified and unmodified aggregate-asphalt binder for both types of asphalt binders is similar.

7. Using hydrophobic coating of calcium carbonate has caused a reduction in debonding energy of samples. The greatest changes are in samples made by lime aggregates and asphalt binders $85-100$ and 60-70, respectively.

8. Samples Made by asphalt binder 60-70 have less debonding energy compared to samples made by asphalt binder 85-100. This means that damage potential of samples made by asphalt binder $60-70$ is less than that of samples made by asphalt binder 85-100.

9. Results obtained by 2 methods show a proper correlation between mechanical and thermodynamic methods.

\section{Refrences}

[1] Ziari, H., Hayati, P., Sobhani, J. "Air-Entrained Air Field SelfConsolidating Concrete Pavements: Strength and Durability", International Journal of Civil Engineering, 15(1), pp. 21-33, 2016. https://doi.org/10.1007/s40999-016-0104-4

[2] Hamedi, Gh. H., Tahami, S. A. "The effect of using anti-stripping additives on moisture damage of hot mix asphalt", International Journal of Adhesion and Adhesives, 81, pp. 90-97, 2018. https://doi.org/10.1016/j.ijadhadh.2017.03.016

[3] Tang, T., Zha, X., Xiao, Q., Chen, Y. "Laboratory Characterization and Field Validation of ROADMESH-Reinforced Asphalt Pavement in China", International Journal of Civil Engineering, 16(3), pp. 299-313, 2018.

https://doi.org/10.1007/s40999-016-0128-9

[4] Kumar,. P, Anand, P. "Laboratory study on moisture susceptibility of dense graded mixes", Journal of Transportation Engineering, 138(1), pp. 105-113, 2012. https://doi.org/10.1061/(ASCE)TE.1943-5436.0000306

[5] Bhasin, A. "Development of methods to quantify bitumen-aggregate adhesion and loss of adhesion due to water", PhD Dissertation, Texas A\&M University, 2006.

[6] Cheng, D., Little, D. N., Lytton, R.L., Holste, J. C. "Moisture Damage Evaluation of Asphalt Mixture by Considering both Moisture Diffusion and repeated Load Conditions", Transportation Research Board of the National Academies, 1832, pp. 42-58, 2003. https://doi.org/10.3141/1832-06

[7] Shakiba, M. "A continuum coupled moisture-mechanical damage constitutive model for asphalt concrete", $\mathrm{PhD}$ Dissertation, Texas A\&M University, 2013.

[8] Kanitpong, K., Bahia, H. U. "Role of adhesion and thin film tackiness of asphalt binders in moisture damage of HMA", Association of Asphalt paving Technologists, 72, pp. 611-642, 2003. http:// worldcat.org/issn/02702932

[9] Solaimanian, M., Bonaquist, R. F., Tandon, V. "Improved conditioning and testing procedures for HMA moisture Susceptibility", Transportation Research Board, Washington DC, NCHRP Report 589, 2007.

https://doi.org/10.17226/23153

[10] Bagampadde, U. "Investigations on moisture damage-related behaviour of bituminous materials", Phd thesis, KTH Royal Institute of Technology, Civil and Architectural Engineering, 2005.

[11] Kok, B. V., Yilmaz, M. "The effects of using lime and styrenebutadiene-styrene on moisture sensitivity resistance of hot mix asphalt", Construction and Building Materials, 23(5), p. 19992006, 2009.

https://doi.org/10.1016/j.conbuildmat.2008.08.019 
[12] Sebaaly, P. E. "Comparison of lime and liquid additives on the moisture damage of hot mix asphalt mixtures", National Lime Association, Reno, Nevada USA, 2007.

[13] Arabani, M., Tahami, S. A., Hamedi, G. H. "Performance evaluation of dry process crumb rubber-modified asphalt mixtures with nanomaterial", Road Materials and Pavement Design, 19(5), pp. 1241-1258, 2017. https://doi.org/10.1080/14680629.2017.1302356

[14] Kim, Y.-R., Lutif, J. S., Bhasin, A., Little, D. N. "Evaluation of moisture damage mechanisms and effects of hydrated lime in asphalt mixtures through measurements of mixture component properties and performance testing", Journal of Materials in Civil Engineering, 20(10), pp. 659-667, 2008. https://doi.org/10.1061/(ASCE)0899-1561(2008)20:10(659)

[15] Hamedi, G. H., Moghadas Nejad, F. "Evaluating the Effect of Mix Design and Thermodynamic Parameters on Moisture Sensitivity of Hot Mix Asphalt", Materials in Civil Engineering Journal, 29(2), pp. 1-11, 2017. https://doi.org/10.1061/(ASCE)MT.1943-5533.0001734

[16] Al-Qadi, I. L., Abuawad, I. M., Dhasmana, H., Coenen, A. R., Trepanier, J. S. "Effects of Various Asphalt Binder Additives/ Modifiers on Moisture-Susceptible Asphaltic Mixtures", Illinois Center for Transportation, Illinois, U.S.A, 2014.

[17] Bhasin, A., Little, D. N. "Application of Microcalorimeter to Characterize Adhesion Between Asphalt Binders and Aggregates", Materials in Civil Engineering, 21(6), pp. 235-243, 2009. https://doi.org/10.1061/(ASCE)0899-1561(2009)21:6(235)

[18] Wasiuddin, N. M., Fogel, C. M., Zaman, M. M., O’Rear, E. A. "Effect of Anti-Strip Additives on surface Free Energy Characteristics of Asphalt Binders for Moisture-Induced Damage Potential", Journal of Testing and Evaluation. 35(1), pp. 36-44, 2007. https://doi.org/10.1520/JTE100290

[19] Bhasin, A., Little, D. N., Vasconcelos, K. L., Masad. E. "Surface Free Energy to Identify Moisture Sensitivity of Materials for Asphalt Mixes", Transportation Research Board. 2001(1), pp. 37-45, 2007.

https://doi.org/10.3141/2001-05
[20] Bhasin, A., Howson, J., Masad, E., Little, D. N., Lytton, R. L. "Effect of Modification Processes on Bond Energy of Asphalt Binders", Transportation Research Board. 1998(1), pp. 29-37, 2007.

https://doi.org/10.3141/1998-04

[21] ASTM "D1559-89 Test Method for Resistance of Plastic Flow of Bituminous Mixtures Using Marshall Apparatus", in Annual Book of ASTM Standards, America: American Society for Testing and Materials, 1998.

[22] Santucci, L. "Minimizing Moisture Damage in Asphalt Pavements", Technology Transfer Program, 2(2), 2010.

[23] Lytton, R. L., Masad, E. A., Zollinger, C., Bulut, R., Little, D. N. "Measurements of surface energy and its relationship to moisture damage", Texas Transportation Institute A \& M University System, Texsas, U.S.A, 2005.

[24] Van Oss, C. J., Chaudhury, M. K., Good, R. J. "Interfacial Lifshitzvan der Waals and polar interactions in macroscopic systems", Chemical Review, 88(6), pp. 927-941, 1988. https://doi.org10.1021/cr00088a006

[25] Gorkem, C., Sengoz, B. "Predicting stripping and moisture induced damage of asphalt concrete prepared with polymer modified bitumen and hydrated lime", Construction and Building Materials, 23(6), pp. 2227-2236, 2009. https://doi.org/10.1016/j.conbuildmat.2008.12.001

[26] Peltonen, P. V. "Road aggregate choice based on silicate quality and bitumen adhesion", Journal of transportation engineering, 118(1), pp. 50-61, 1992.

https://doi.org/10.1061/(ASCE)0733-947X(1992)118:1(50)

[27] Hamedi, G. H. "Investigating the Use of Nano Coating Over the Aggregate Surface on Moisture Damage of Asphalt Mixtures", International Journal of Civil Engineering, 16(6), pp. 659-669, 2018.

https://doi.org/10.1007/s40999-016-0143-x

[28] Jakarni, F. M. "Adhesion of asphalt", PhD thesis, University of Nottingham, Nottingham, U.K., 2012. 